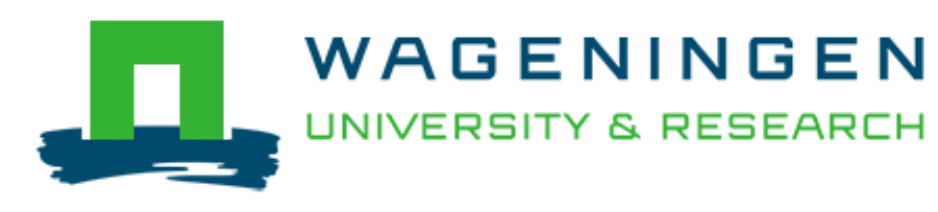

Antibacterial prenylated stilbenoids from peanut (Arachis hypogaea)

de Bruijn, W. J. C., Araya-Cloutier, C., Bijlsma, J., de Swart, A., Sanders, M. G., de Waard, P., ... Vincken, J. P.

This is a "Post-Print" accepted manuscript, which has been published in "Phytochemistry Letters"

This version is distributed under a non-commercial no derivatives Creative Commons (c) (1) @) ( 9 (CC-BY-NC-ND) user license, which permits use, distribution, and reproduction in any medium, provided the original work is properly cited and not used for commercial purposes. Further, the restriction applies that if you remix, transform, or build upon the material, you may not distribute the modified material.

Please cite this publication as follows:

de Bruijn, W. J. C., Araya-Cloutier, C., Bijlsma, J., de Swart, A., Sanders, M. G., de Waard, P., ... Vincken, J. P. (2018). Antibacterial prenylated stilbenoids from peanut (Arachis hypogaea). Phytochemistry Letters, 28, 13-18. DOI:

10.1016/j.phytol.2018.09.004

You can download the published version at:

https://doi.org/10.1016/j.phytol.2018.09.004 


\section{Antibacterial prenylated stilbenoids from peanut (Arachis hypogaea)}

Wouter J. C. de Bruijn ${ }^{\mathrm{a}}$, Carla Araya-Cloutier ${ }^{\mathrm{a}}$, Judith Bijlsma ${ }^{\mathrm{a}}$, Anne de Swart ${ }^{\mathrm{a}}$, Mark G. Sanders $^{\mathrm{a}}$, Pieter de Waard ${ }^{\mathrm{b}}$, Harry Gruppen ${ }^{\mathrm{a}}$, Jean-Paul Vincken ${ }^{\mathrm{a}}{ }^{*}$

${ }^{\text {a }}$ Laboratory of Food Chemistry, Wageningen University, P.O. Box 17, 6700 AA Wageningen, The Netherlands

b MAGNEFY (MAGNEtic resonance research FacilitY), Wageningen University, Wageningen, The Netherlands

* Corresponding author: e-mail jean-paul.vincken@wur.nl; tel. +31 (0)317 482234 


\section{Abstract}

2 Stilbenoids are a class of secondary metabolites with a stilbene backbone that can be produced

3 by peanut (Arachis hypogaea) as defence metabolites. Six monomeric prenylated stilbenoids,

4 including the compound arachidin-6 (4), were isolated from extracts of fungus-elicited peanuts

5 (Arachis hypogaea) using preparative liquid chromatography. Their structures were confirmed

6 by $\mathrm{MS}^{\mathrm{n}}, \mathrm{HRMS}$ and NMR spectroscopy and their antibacterial activity was evaluated against

7 methicillin-resistant Staphylococcus aureus (MRSA). Similarly to other phenolic compounds,

8 prenylated derivatives of stilbenoids were more active than their non-prenylated precursors

9 piceatannol, resveratrol, and pinosylvin. Chiricanine A (6), a chain-prenylated pinosylvin

10 derivative, was the most potent compound tested, with a minimum inhibitory concentration

11 (MIC) of $12.5 \mu \mathrm{g} \mathrm{mL}^{-1}$. Arachidin-6 (4), a ring-prenylated piceatannol derivative, had moderate

12 potency (MIC 50-75 $\mu \mathrm{g} \mathrm{mL}^{-1}$ ). In conclusion, prenylated stilbenoids represent a group of 13 potential natural antibacterials which show promising activity against MRSA.

\section{Highlights}

- New stilbenoid: arachidin-6, a ring-prenylated piceatannol derivative.

- Antibacterial activity of purified prenylated stilbenoids assessed against MRSA.

- Chiricanine A (MIC $12.5 \mu \mathrm{g} \mathrm{mL}^{-1}$ ) and other stilbenoids are active against MRSA.

\section{Keywords}

Leguminosae, natural product, secondary metabolite, stilbene, prenylation, antimicrobial 


\section{Introduction}

Stilbenoids, a class of secondary metabolites with a stilbene backbone (Figure 1A), can be produced by peanut (Arachis hypogaea) as defence metabolites (Sobolev, 2013). Analogous to phenolic metabolites of other members of the Leguminosae family, e.g. soy bean and mung bean (Aisyah et al., 2016; Simons et al., 2011), the production of stilbenoids and, in particular, their prenylated derivatives can be stimulated by fungal elicitation of germinating peanut seeds (Aisyah et al., 2015; Sobolev et al., 2016; Sobolev et al., 2010). Prenylation refers to the attachment of a prenyl-moiety (i.e. 3,3-dimethylallyl) by a prenyltransferase and in the case of peanut stilbenoids occurs mainly at the 4-position (Yang et al., 2016) as in, for example, arachidin-2 (Figure 1B, compound 2) (Sobolev et al., 2016). Prenylation of phenolic compounds has been shown to increase their antibacterial activity, which is exemplified by the minimum inhibitory concentrations (MICs) of genistein ( $\mathrm{MIC}>128 \mu \mathrm{g} \mathrm{mL}^{-1}$ ), 6-prenylgenistein (MIC $32 \mu \mathrm{g} \mathrm{mL}^{-1}$ ), and 6,8-diprenyl-genistein (MIC $8 \mu \mathrm{g} \mathrm{mL}^{-1}$ ) against methicillinresistant Staphylococcus aureus (MRSA) (Hatano et al., 2000). More generally, prenylated (iso)flavonoids have been shown to possess antibacterial activity against antibiotic-resistant strains of S. aureus and other pathogenic gram-positive bacteria (Araya-Cloutier et al., 2017; Araya-Cloutier et al., 2018a; Gibbons, 2004). An extract from fungus (Rhizopus) elicited peanut seedlings, enriched in prenylated stilbenoids, already showed promising antibacterial activity against E. coli, L. monocytogenes and MRSA (Araya-Cloutier et al., 2017; Araya-Cloutier et al., 2018b). In this study, we have isolated and characterized several prenylated compounds with different stilbenoid precursors and prenyl configurations from an extract of Rhizopuselicited peanut seedlings and assessed their antibacterial activity against MRSA. In analogy with other phenolic compounds, we hypothesize that prenylation of stilbenoids will enhance their antibacterial activity. 


\section{Results and discussion}

\subsection{Sample Clean-up, Pre-purification and Purification by Preparative RP-HPLC}

The crude extract of Rhizopus-elicited peanut seedlings showed a chromatographic profile on RP-UHPLC comparable to what was described previously (Aisyah et al., 2015). The clean-up with ethyl acetate effectively removed the majority of polar impurities in the extract, yielding the cleaned extract which contained mainly prenylated stilbenoids (Figure S1, supplementary data, 6-19 min) and apolar impurities (Figure S1, 19-28 min) which, based on LC-MS analysis, were mostly lipids like oxylipins and free fatty acids (Murphy, 2014). After pre-purification by Flash chromatography, most of the apolar impurities were removed and several pools were obtained enriched in mixtures of prenylated stilbenoids and some oxylipins (Figure S1). After subjecting these pools to preparative RP-HPLC separation, six purified compounds were obtained.

\subsection{Structure Elucidation of the Prenylated Stilbenoids}

The six compounds that were isolated were first analysed by UHPLC-PDA-ESI-IT-MS, the corresponding spectrometric and spectroscopic data of which is shown in Table 1. Based on the comparison of this data to literature (Aisyah et al., 2015; Sobolev et al., 2009; Sobolev et al., 2006), the compounds were tentatively annotated. For most purified compounds, the trans isomer was most abundant but the cis isomer was also present. The two isomers were distinguished by their $\lambda_{\max }$, and the peak with the higher $\lambda_{\max }$ was assigned as the trans isomer, in accordance with previously reported data (Trela and Waterhouse, 1996). Based on $U V_{310}$ area compound $\mathbf{1}$ was approximately $60 \%$ trans, compound $\mathbf{3}$ was approximately $88 \%$ trans, and compounds 2, 4, 5 and $\mathbf{6}$ were all more than 97\% trans. Spectrometric and spectroscopic data provided is based on the trans isomer.

In ESI-IT-MS (Table 1), the most abundant fragments observed for compounds 1-3 and $\mathbf{6}$ in negative ionisation mode were those with a neutral loss (NL) of $56 \mathrm{u}\left(\mathrm{C}_{4} \mathrm{H}_{8}\right)$ and NL of 69 or 
$70 \mathrm{u}$, corresponding to complete loss of the prenyl chain (as $\mathrm{C}_{5} \mathrm{H}_{8}$ or $\mathrm{C}_{5} \mathrm{H}_{9}$ ). In positive ionisation mode the main fragments were also related to the prenyl-moiety, resulting in a NL of $56 \mathrm{u}\left(\mathrm{C}_{4} \mathrm{H}_{8}\right)$, as described previously for chain-prenylated (iso)flavonoids (Simons et al., 2009). For compounds 4 and 5 the main fragment observed in positive ionisation mode, $m / z$ 201, corresponded to loss of the catechol ( $\mathrm{NL} 110 \mathrm{u}, \mathrm{C}_{6} \mathrm{H}_{4} \mathrm{O}_{2}$ ) or phenol (NL $94 \mathrm{u}, \mathrm{C}_{6} \mathrm{H}_{4} \mathrm{O}$ ) moiety, respectively. Fragments corresponding to neutral losses of $56 \mathrm{u}$ and $42 \mathrm{u}$ were also observed. For compound 4 the fragment at $m / z 269$ (NL $42 \mathrm{u}$, rel. abundance 25) was more intense than the fragment at $m / z 255$ (NL $56 \mathrm{u}$, rel. abundance 13, not shown in Table 1). The same was observed for compound 5 with the fragments at $m / z 253$ (NL $42 \mathrm{u}$, rel. abundance 51) and $m / z 239$ (NL $56 \mathrm{u}$, rel. abundance 23). The abundance ratio of NL 42:56 u was $>1$ for both compounds, indicating the presence of a ring prenyl rather than a chain prenyl (Simons et al., 2011). In negative ionisation mode, the prenyl-moiety of compounds $\mathbf{4}$ and $\mathbf{5}$ did not readily fragment, instead the unfragmented parent ion, radical fragments and small neutral losses like - $\mathrm{CH}_{3}(15 \mathrm{u}), \mathrm{H}_{2} \mathrm{O}(18 \mathrm{u}), \mathrm{CO}(28 \mathrm{u})$, and $\mathrm{CO}_{2}(44 \mathrm{u})$ were observed.

High resolution mass spectrometric data, as determined by UHPLC-ESI-FTMS, confirmed the expected molecular formulae of all six compounds (Table 1). To confirm the tentative annotations of the structures, ${ }^{1} \mathrm{H}$ NMR spectra of compounds 1-6 were acquired. The structure of compounds 1-3, 5 and 6 was confirmed by comparison of their ${ }^{1} \mathrm{H}$ NMR spectra to published data (Chang et al., 2006; Park et al., 2011; Royer et al., 2010; Sobolev et al., 2009). Compound $4\left(\mathrm{C}_{19} \mathrm{H}_{18} \mathrm{O}_{4}\right.$ based on FTMS), however, which was previously tentatively annotated as 4isopentadienyl-3,5,3',4'-tetrahydroxystilbene (IPP) based on UHPLC-PDA-ESI-IT-MS (Aisyah et al., 2015), did not match this compound's expected ${ }^{1} \mathrm{H}$ NMR spectrum. HMBC and HMQC were performed in order to elucidate the structure of compound 4 (see Table 2 for the ${ }^{1} \mathrm{H}$ and ${ }^{13} \mathrm{C}$ NMR spectroscopic data). The ${ }^{13} \mathrm{C}$ NMR spectrum showed signals identical to those described for the catechol moiety of arachidin-1 (Chang et al., 2006). These signals were 
thereby assigned as aromatic carbons $\mathrm{C}-1^{\prime}$ to $\mathrm{C}-6^{\prime}$. Based on the HMBC and HMQC cross peaks of these carbons, the three ${ }^{1} \mathrm{H}$ NMR signals at $\delta_{\mathrm{H}} 6.974\left(\mathrm{~d}, J=2.0 \mathrm{~Hz}, \mathrm{H}-2^{\prime}\right), 6.737(\mathrm{~d}, J=8.2$ $\left.\mathrm{Hz}, \mathrm{H}-5^{\prime}\right)$, and 6.835 (dd, $J=8.2$ and $2.0 \mathrm{~Hz}, \mathrm{H}-6^{\prime}$ ) were assigned as the corresponding protons. The olefin carbons $\mathrm{C}-\alpha\left(\delta_{\mathrm{C}} 126.75\right)$ and C- $\alpha^{\prime}\left(\delta_{\mathrm{C}} 129.69\right)$ showed HMQC cross peaks with two doublet proton signals at $\delta_{\mathrm{H}} 6.721(J=16.2 \mathrm{~Hz}, \mathrm{H}-\alpha)$ and $6.889\left(J=16.2 \mathrm{~Hz}, \mathrm{H}-\alpha^{\prime}\right)$, whose coupling constants confirmed the trans-olefin. Both of these protons showed cross peaks with aromatic carbons $\mathrm{C}-1^{\prime}$ and $\mathrm{C}-1\left(\delta_{\mathrm{C}} 140.23\right)$. Proton $\mathrm{H}-\alpha$ also showed HMBC cross peaks with ${ }^{13} \mathrm{C}$ NMR signals $\delta_{\mathrm{C}} 106.47$ (C-6) and 106.79 (C-2). The ${ }^{1} \mathrm{H}$ NMR signals $\delta_{\mathrm{H}} 6.418$ (bs, H-2) and $6.475(\mathrm{~d}, J=1.3 \mathrm{~Hz}, \mathrm{H}-6)$ were assigned by their HMQC cross peaks to C-2 and C-6, respectively. These chemical shifts and their HMBC cross peaks were comparable to those described for arahypin-5 (Sobolev et al., 2009). Analogous to arahypin-5 and arachidin-1 the carbon signal $\delta_{\mathrm{C}} 110.23(\mathrm{C}-4)$ showed HMBC cross peaks with H-2 and H-6 and did not have any HMQC cross peaks, indicating that the prenyl was attached at $\mathrm{C}-4$. The remaining ${ }^{13} \mathrm{C}$ NMR signals were consistent with spectroscopic data of C-3 $\left(\delta_{C} 155.26\right), C-5\left(\delta_{C} 154.42\right)$ and the five carbons of the prenyl group reported for arahypin-5 (Sobolev et al., 2009). The signal of C-3" $\left(\delta_{\mathrm{C}} 76.77\right)$ was downfield compared to arachidin-1, which indicated that the prenyl was cyclised to a pyran as in arahypin-5. The remaining ${ }^{1} \mathrm{H}$ NMR signals and their HMBC cross peaks corresponded to those described for arahypin-5 (Sobolev et al., 2009). To the best of our knowledge the elucidated structure, a ring-prenylated piceatannol derivative, has not been previously reported. Consequently, compound 4 was identified as the new compound, 7-[(E)2-(3,4-dihydroxyphenyl)ethenyl]-2,2-dimethylchromen-5-ol, herein named arachidin-6. The structures of compounds 1-6 are shown in Figure 1B.

Prenyl chains in (iso)flavonoids and chalcones have been described to be liable to cyclisation under acidic conditions (Popłoński et al., 2018; Singhal et al., 1980). Thus, it might be argued compound 4 might be an artefact formed due to the addition of $1 \%(v / v)$ formic acid in the 
119 preparative chromatography eluent. Acid-catalysed cyclisation of a prenyl chain, however, 120 typically yields a dihydropyran (Popłoński et al., 2018; Singhal et al., 1980), whereas the prenyl

121 in compound $\mathbf{4}$ is present as a pyran as evidenced by the structure elucidation. It was, therefore,

122 concluded that the compound as such was present in the elicited peanut seedlings.

123

124

125

126

127

128

\subsection{Stability and Antibacterial Activity of Prenylated Stilbenoids}

During the purification process, the prenylated stilbenoids were prone to both trans-cis isomerisation, as was previously reported (Trela and Waterhouse, 1996), and dimerization. The compounds' reactivity could potentially be of influence on their antimicrobial activity. Therefore, the stability of the compounds during the antibacterial assay was assessed by incubating them under normal assay conditions. Under these conditions, no further trans to cis isomerisation or dimerization was observed for compounds 2-6 (Figure S2, supplementary data). Arachidin-1 (1) was not included due to low amounts of available material. However, we assumed its stability during the assay would be similar to that of the other five compounds.

Thus, we did not expect any influence of isomerization or dimerization on the antibacterial assay results.

The antibacterial activity of arachidin-1 (1), arachdin-2 (2), arachidin-3 (3), arachidin-6 (4), arahypin-5 (5), and chiricanine A (6) against MRSA was assessed. For reference, nonprenylated stilbenoids piceatannol (precursor of arachidin-1 (1) and -6 (4)), resveratrol (precursor of arachidin-2 (2) and -3 (3) and arahypin-5 (5)), and pinosylvin (precursor of chiricanine A (6)) were also tested. The resulting MIC and TTD values are shown in Table 3, together with some structural properties of these molecules. For resveratrol and piceatannol, no MIC was found below $200 \mu \mathrm{g} \mathrm{mL}$. Therefore, they were considered not to be active antibacterials. The attachment of a prenyl-moiety to these precursors increased the resulting molecule's antibacterial activity, as expected. For example, resveratrol had an MIC of $>200$ $\mu \mathrm{g} \mathrm{mL} L^{-1}(>877 \mu \mathrm{M})$ and its ring-prenylated derivative arahypin-5 (5) had an MIC of 25-50 $\mu \mathrm{g}$ 
$144 \mathrm{~mL}^{-1}(85-170 \mu \mathrm{M})$, thus the prenyl group enhanced activity by up to ten fold in this case. No

145 MIC was found below $50 \mu \mathrm{g} \mathrm{mL}^{-1}$ for arachidin-1 (1), arachidin-2 (2), or arachidin-3 (3). Based

146 on the $\mathrm{TTD}_{50}$ (time-to-detection at $50 \mu \mathrm{g} \mathrm{mL}^{-1}$ ) values of these compounds, arachidin-2 (2) was

147 the most active of the three. In addition, the $\mathrm{TTD}_{50}$ and $\mathrm{TTD}_{25}$ values obtained for these

148 compounds indicated that they were less active than compounds 4-6 and, especially arachidin-

1491 (1) and arachidin-3 (3), were only marginally more active than non-prenylated resveratrol and

150 piceatannol. The new compound, arachidin-6 (4), showed moderate activity with MIC at 50-75

$151 \mu \mathrm{g} \mathrm{mL} \mathrm{m}^{-1}$. The prenylated pinosylvin derivative, chiricanine $\mathrm{A}(\mathbf{6})$, was the most active

152 compound tested in this work with an observed MIC of $12.5 \mu \mathrm{g} \mathrm{mL}^{-1}(44 \mu \mathrm{M})$ against MRSA,

153 which is quite promising and in range of that of some traditional antibiotics (Braga et al., 2005).

\subsection{Structure-Activity Relationships of Prenylated Stilbenoids against MRSA}

155

The antimicrobial activity of prenylated phenolics has been related to the increased hydrophobicity conferred by the addition of the prenyl-group (Botta et al., 2005). Chiricanine

A (6) possessed the highest $\log \mathrm{D}_{7.2}$ of the six purified compounds. The anti-MRSA activity of compounds 1-6 (expressed as TTD 25 , using $24 \mathrm{~h}$ if TTD > $24 \mathrm{~h}$ ) was, however, not correlated to their $\log \mathrm{D}_{7.2}(\mathrm{r}=0.002)$. The lack of a correlation between activity and hydrophobicity has been previously described for prenylated phenolic compounds (Araya-Cloutier et al., 2018b). The configuration of the prenyl-moiety (chain or ring) seems to have an effect on the observed antibacterial activity. Ring prenylation was found to be more effective than chain prenylation, as demonstrated when comparing molecules with the same stilbenoid precursor: arachidin-1 (1) (chain, $\mathrm{TTD}_{25} 6.1 \mathrm{~h}$ ) vs. arachidin-6 (4) (ring, $\mathrm{TTD}_{25} 11.5 \mathrm{~h}$ ) and arachidin-2 (2) or -3 (3) (chain, $\mathrm{TTD}_{25} 7.4$ or $6.6 \mathrm{~h}$, respectively) vs. arahypin-5 (5) (ring, TTD 259.6 - >24 h) (Table 3). This was in contrast with previous results which indicated that chain-prenylated (iso)flavonoids were

167 generally more active than ring-prenylated ones (Araya-Cloutier et al., 2018a; Araya-Cloutier 168 et al., 2018b). The effect of a 3-methyl-1-butene (arachidin-1 (1) and -3 (3)) or a 3-methyl-2- 
169 butene (arachidin-2 (2)) type prenyl chain was not completely clear but the higher TTD 50 of

170 arachidin-2 indicated that a 3-methyl-2-butene chain might result in better activity than a 3-

171 methyl-1-butene chain.

172 The stilbenoid precursor of the prenylated compounds might also affect their activity. So far,

173 our results indicated that the order of activity for the three tested precursors is pinosylvin >

174 resveratrol > piceatannol. Within the group of compounds 1-6, the number of hydrogen bond

175 donors is negatively correlated with $\operatorname{TTD}_{25}(\mathrm{r}=-0.89)$, i.e. having less hydrogen bond donors

176 seems to result in better anti-MRSA activity. This matches previously described results for

177 pterostilbene (i.e. 3,5-dimethyl-resveratrol, MIC $78 \mu \mathrm{M}$ ) which was found to be up to 16 times

178 more active against MRSA than resveratrol in that study (MIC 1,250 $\mu \mathrm{M}$ ) (Yang et al., 2017).

179 The structure-antibacterial activity relationships described above indicate that prenylated

180 stilbenoids from the pinosylvin precursor seem to be most potent. In addition, ring prenylation

181 seems to confer more antibacterial potential than chain prenylation. A candidate anti-MRSA

182 molecule reported in literature would be arahypin-13 (ring-prenylated pinosylvin) (Sobolev et

183 al., 2016). This molecule might show similar or even more potent activity than chiricanine A.

184 To establish quantitative structure-activity relationships, evaluation of a larger set of

185 compounds will be necessary. 


\section{Conclusion}

187 Similarly to other phenolic compounds, prenylation of stilbenoids enhances their antibacterial 188 activity. Prenylated stilbenoids represent a group of natural potential antibacterials with activity

189 against the antibiotic-resistant gram-positive bacterium MRSA. The newly discovered 190 prenylated stilbenoid, arachidin-6, was moderately potent with an MIC of 50-75 $\mu \mathrm{g} \mathrm{mL}^{-1}$ 191 against MRSA, whereas the activity of chiricanine A, with its MIC of $12.5 \mu \mathrm{g} \mathrm{mL}^{-1}$, is in range

192 with some traditional antibiotics. Within the set of stilbenoids assessed in this work prenylation 193 enhanced antimicrobial activity. Hydrophobicity was not correlated with antimicrobial activity, 194 whereas ring-prenylation seems to convey a larger increase in activity than chain-prenylation. 


\section{Experimental}

196

\subsection{General Experimental Procedures}

NMR Spectra were recorded on a Bruker Avance-III-600 spectrometer, equipped with a cryoprobe. Compounds 1, 2, 4, and 5 were dissolved in $0.5 \mathrm{~mL}$ methanol-d 4 (99.9 atom\%, Isotec); compounds 3 and 6 were dissolved in $0.5 \mathrm{~mL}$ chloroform-d (99.9 atom\%, Isotec). ${ }^{1} \mathrm{H}$ and ${ }^{13} \mathrm{C}$ NMR spectra were recorded at a probe temperature of $300 \mathrm{~K}$. Chemical shifts are expressed in ppm relative to internal TMS at $0.00 \mathrm{ppm}$, but were actually measured to the residual solvent signals of methanol $(\delta \mathrm{C}=49.00 \mathrm{ppm}, \delta \mathrm{H}=3.31 \mathrm{ppm})$ or chloroform $(\delta \mathrm{C}=77.16 \mathrm{ppm}, \delta \mathrm{H}=$ $7.26 \mathrm{ppm})$. For all compounds, $1 \mathrm{D}{ }^{1} \mathrm{H}$ spectra were acquired. For compound 4, additional 1D ${ }^{13} \mathrm{C}$ and 2D COSY, HMBC, and HMQC spectra were acquired. ESI-IT-MS ${ }^{\mathrm{n}}$ spectra were acquired on an LTQ Velos Pro linear ion trap mass spectrometer (Thermo Scientific, San Jose, CA, USA) equipped with a heated ESI probe coupled in-line to the Accela RP-UHPLC system (Thermo Scientific). The Accela UHPLC system was used in the same configuration as previously described (de Bruijn et al., 2016). The flow rate was $300 \mu \mathrm{L} \mathrm{min}^{-1}$ at a column temperature of $35^{\circ} \mathrm{C}$. Eluents used were water (A) and $\mathrm{MeOH}(\mathrm{B})$, both with $0.1 \%(v / v)$ formic acid. The elution profile can be found in the supplementary data. Detection wavelengths for UV-Vis were set to the range of 200-600 $\mathrm{nm}$ and data were recorded at $20 \mathrm{~Hz}$. High resolution mass data were acquired on a Thermo Q Exactive Focus hybrid quadrupole-orbitrap mass spectrometer (Thermo Scientific) equipped with a heated ESI probe (ESI-FTMS) coupled inline to the Vanquish RP-UHPLC system. The Vanquish UHPLC system (Thermo Scientific) in the same configuration and with the same column as described previously (de Bruijn et al., 2016). The samples were eluted with water (A) and ACN (B), both with $0.1 \%(v / v)$ formic acid with a flow rate of $400 \mu \mathrm{L} \mathrm{min}{ }^{-1}$ at $45^{\circ} \mathrm{C}$. The elution profile can be found in the supplementary data. A Waters Acquity BEH C18 $2.1 \times 150 \mathrm{~mm}, 1.7 \mu \mathrm{m}$ particle size column with a Waters VanGuard $2.1 \times 5 \mathrm{~mm}$ guard column of the same material was used for all analytical RP- 
UHPLC separations. Flash chromatography was performed on a Reveleris Flash 221 chromatography system (Grace, Columbia, MD, USA). A Reveleris C18 RP 80 g cartridge (particle size $40 \mu \mathrm{m}$ ) was eluted with water (A) and $\mathrm{MeOH}(\mathrm{B})$, both with $1 \%(v / v)$ formic acid, at room temperature at a flow rate of $60 \mathrm{~mL} \mathrm{~min}^{-1}$. Preparative chromatography was performed on a Waters preparative RP-HPLC-MS system (Waters, Milford, MA, USA) as previously described (van de Schans et al., 2016). The column used was a Waters XBridge Prep C18 OBD 226 column $(19 \times 250 \mathrm{~mm}, 5 \mu \mathrm{m}$ particle size $)$ and was eluted with water $(\mathrm{A})$ and $\mathrm{ACN}(\mathrm{B})$, both 227 with $1 \%(v / v)$ formic acid, at room temperature at a flow rate of $17 \mathrm{~mL} \mathrm{~min}^{-1}$.

\subsection{Chemicals}

229 Sodium hypochlorite 47/50\% (w/v) solution ( 13\% active Cl) was obtained from Chem-Lab 230 (Zedelgem, Belgium). Technical grade $n$-hexane 98\% ( $v / v)$ was obtained from VWR 231 International (Radnor, PA, USA). UHPLC-MS grade solvents and HPLC grade ACN (for 232 preparative chromatography) were purchased from Biosolve (Valkenswaard, The Netherlands). 233 trans-Piceatannol $>98 \%(w / w)$ and trans-resveratrol $\geq 98 \%(w / w)$ were purchased from Cayman 234 Chemical (Ann Arbor, MI, USA). trans-Pinosylvin $\geq 97 \%(w / w)$ and tert-butanol $\geq 98 \%(w / w)$ 235 were purchased from Sigma-Aldrich (St. Louis, MO, USA). Water (MQ) for other purposes 236 than UHPLC was prepared using a Milli-Q water purification system (Merck Millipore, 237 Billerica, MA, USA). Ethanol absolute $\geq 99.9 \%(v / v)$ was purchased from Merck Millipore.

\section{$238 \quad$ 4.3 Plant and Fungal Material}

239 Peeled peanuts (Arachis hypogaea) with skin for feed purposes were purchased locally. Dried 240 Rhizopus culture was purchased as tempeh starter culture from TopCultures (Zoersel, Belgium). 


\subsection{Peanut Germination and Elicitation with Rhizopus}

242 Peanuts were surface-sterilized by soaking in a $1 \%(w / v)$ hypochlorite solution $\left(5 \mathrm{~L} \mathrm{~kg}^{-1}\right.$ seeds)

243 for $15 \mathrm{~min}$ at room temperature and were then rinsed with demineralized water. Surface244 sterilized peanuts were germinated in the dark in a pilot-scale two-tank steep germinator 245 (Custom Laboratory Products, Keith, UK). The cleaning procedure, trays, and setup of the 246 germinator were the same as described previously (de Bruijn et al., 2016). In total $3 \mathrm{~kg}$ of 247 peanuts were germinated in two identical experiments. Approximately $300 \mathrm{~g}$ peanuts were 248 placed in each of the five tray compartments that were lined with disinfected cellulose filter 249 paper (Whatman $5951 / 2$, folded, $320 \mathrm{~mm}$ ). The program set in the germinator was as follows: 250 soaking for $16 \mathrm{~h}$ at $25^{\circ} \mathrm{C}$ (aeration $1 \mathrm{~min}$ every $10 \mathrm{~min}$ ), followed by germination for $48 \mathrm{~h}$ at 25 $251{ }^{\circ} \mathrm{C}$. The germinating peanuts were then inoculated by pouring the Rhizopus starter culture $(0.2$ $252 \mathrm{~L} \mathrm{~kg}^{-1}$ peanuts equalling approximately $2 \times 10^{5} \mathrm{CFU} \mathrm{g} \mathrm{g}^{-1}$ peanuts) over them. Prior to 253 application, the starter culture was rehydrated with peptone physiological salt solution (Tritium 254 Microbiologie, Eindhoven, The Netherlands) $\left(100 \mathrm{mg} \mathrm{mL}^{-1}\right)$ and incubated for $1 \mathrm{~h}$ at $37{ }^{\circ} \mathrm{C}$. 255 After fungal inoculation, peanuts were incubated for $72 \mathrm{~h}$ at $30{ }^{\circ} \mathrm{C}$. During the entire process, 256 relative humidity $(\mathrm{RH})$ was controlled by periodical aeration with humidified air, $\mathrm{RH}$ of the air 257 supplied to the tanks was maintained between $60-83 \%$ (monitored by germinator), resulting in $258 \mathrm{RH}$ of $82-95 \%$ inside the tanks (measured externally). The described conditions proved to be 259 effective to ensure germination of the seeds as well as growth of the fungus. At the end of the 260 experiment, the peanuts were frozen and stored at $-20{ }^{\circ} \mathrm{C}$ until further processing.

\section{$261 \quad 4.5$ Extraction and Isolation}

262 Peanut seedlings were extracted according to a method adapted from Sobolev and co263 workers.(Sobolev et al., 2009) In short, the elicited peanut seedlings were defatted by 264 continuous Soxhlet extraction with $n$-hexane for $5 \mathrm{~h}$. The defatted peanut seedlings were then 265 extracted with $\mathrm{MeOH}$ in a blender for $1 \mathrm{~min}(1 \mathrm{~L} \mathrm{MeOH}$ per $200 \mathrm{~g}$ seedlings). The suspension 
was filtered over a paper filter under reduced pressure and the retentate peanut pulp was subjected to one more identical extraction. The methanolic extracts were combined and defatted once more by liquid-liquid partitioning with $n$-hexane (hexane:MeOH, 1:3). The defatted methanolic extract was filtered over cellulose filter paper (Whatman 595 1/2, folded, $320 \mathrm{~mm}$ ) and the $\mathrm{MeOH}$ was evaporated under reduced pressure to yield the crude extract. Exposure to 271 light was avoided where possible during further sample preparation and purification. In order 272 to remove polar impurities, the dried crude extract was then suspended in ethyl acetate (33 $\mathrm{mg}$ $\left.\mathrm{mL}^{-1}\right)$, subjected to an ultrasonic bath for $10 \mathrm{~min}$, and centrifuged $(10 \mathrm{~min}, 4,000 \times g)$. The supernatant, containing the prenylated stilbenoids, was collected while the pellet, containing mostly polar impurities, was discarded. The supernatant was evaporated to dryness under reduced pressure, recollected using tert-butanol and lyophilised to yield the cleaned extract. Cleaned extracts were pre-purified using Flash chromatography. The sample was solubilised in $\mathrm{MeOH}$ acidified with $1 \%(v / v)$ FA (final sample concentration $300-500 \mathrm{mg} \mathrm{mL}^{-1}$ ) and was manually injected (1.0-2.5 g per run). The elution profile used can be found in the supplementary data. The collected fractions were analysed by RP-UHPLC-PDA-ESI-IT-MS ${ }^{\mathrm{n}}$ 281 and those containing similar compounds were pooled. The $\mathrm{MeOH}$ was removed under reduced 282 pressure and the remaining water was removed by lyophilisation.

283 The pools obtained from Flash chromatography were further purified using a Waters 284 preparative RP-HPLC system (Waters, Milford, MA, USA) as previously described (van de 285 Schans et al., 2016). Pools were solubilised at $2 \mathrm{mg} \mathrm{mL}^{-1}$ in $50 \%(v / v)$ aqueous $\mathrm{MeOH}$ and 286 injected (2.0-2.5 mL) on a Waters XBridge Prep C18 OBD column $(19 \times 250 \mathrm{~mm}, 5 \mu \mathrm{m}$ particle 287 size) and were eluted with water (A) and ACN (B), both with $1 \%(v / v)$ formic acid, at room 288 temperature at a flow rate of $17 \mathrm{~mL} \mathrm{~min}^{-1}$. The elution profile used for each compound can be 289 found in the supplementary data. Data was acquired and analysed by MassLynx (version 4.1, 290 Waters). The collected fractions were analysed by RP-UHPLC-PDA-ESI-IT-MS ${ }^{\mathrm{n}}$. Based on 
the analysis, fractions containing the same compound were pooled and the $\mathrm{ACN}$ was evaporated under a stream of $\mathrm{N}_{2}$. The remaining water phase was immediately frozen and lyophilised.

\subsection{Micro-Broth Dilution Assay}

294 Compounds 1-6 were tested for their antibacterial activity against the gram-positive bacterium methicillin-resistant Staphylococcus aureus (MRSA) (18HN, spa type t034; RIVM, Bilthoven, The Netherlands), according to a previously described method (Araya-Cloutier et al., 2017). The final inoculum size used was $4.2 \pm 0.2 \log _{10} \mathrm{CFU} \mathrm{mL} \mathrm{m}^{-1}$. Final concentrations tested ranged from 6.25 to $200 \mu \mathrm{g} \mathrm{mL}^{-1}$, depending on the amount of material available, with a maximum of $2.1 \%(v / v)$ ethanol in the final solution. Stock solutions of the tested compounds were prepared in $70 \%(v / v)$ aqueous ethanol. Prior to the micro-broth dilution assay, the stocks were diluted in tryptone soy broth (TSB) (Oxoid, Basingstoke, UK). Equal volumes (100 $\mu \mathrm{L})$ of the diluted compound and of inoculum were transferred to each well of a 96-well plate. Inoculum with vancomycin (VWR International) (final concentration of $4 \mu \mathrm{g} \mathrm{mL}^{-1}$ ) was used as a positive control. Inoculum with sterile TSB containing 2.1\% $(v / v)$ ethanol was used as a negative control. All compounds were tested in at least two independent biological replicates. The 96well plate was covered with a gas-permeable imaging seal (4Titude, Wotton, UK) and incubated in a SpectraMax M2e (Molecular Devices, Sunnyvale, CA, USA) at $37{ }^{\circ} \mathrm{C}$ for $24 \mathrm{~h}$ with 308 constant linear shaking. The optical density at $600 \mathrm{~nm}\left(\mathrm{OD}_{600}\right)$ was measured every $5 \mathrm{~min}$. 309 Time-to-detection (TTD) was defined as the time (h) to reach a difference of 0.05 units from 310 the initial $\mathrm{OD}_{600}$ (Araya-Cloutier et al., 2017; Araya-Cloutier et al., 2018b). If no measurable 311 increase in $\mathrm{OD}_{600}$ was observed, the TTD was defined as $>24 \mathrm{~h}$ and the tested concentration 312 was considered to be inhibitory. The minimum inhibitory concentration (MIC) was defined as 313 the lowest concentration of each compound that was found to be inhibitory. The TTD of the 314 negative control with $2.1 \%(v / v)$ ethanol was $5.6 \mathrm{~h}$ (standard deviation $\pm 0.1 \mathrm{~h}$ ) (average of four 
315 independent biological replicates, each with triplicates). For comparison of the compounds,

316 TTD at concentrations of 25 and $50 \mu \mathrm{g} \mathrm{mL}^{-1}$, respectively $\mathrm{TTD}_{25}$ and $\mathrm{TTD}_{50}$, were determined. 


\section{Supplementary data}

318 Elution profiles used for preparative and analytical liquid chromatography. UHPLC-ESI-IT-

319 MS chromatograms of cleaned peanut extract and Flash pools (Figure S1). UHPLC-PDA

320 chromatogram stability assessment of compounds 2-6 under antibacterial assay conditions

321 (Figure S2). 


\section{References}

Aisyah, S., Gruppen, H., Andini, S., Bettonvil, M., Severing, E., Vincken, J.-P., 2016. Variation in accumulation of isoflavonoids in Phaseoleae seedlings elicited by Rhizopus. Food Chem. 196, 694-701.

Aisyah, S., Gruppen, H., Slager, M., Helmink, B., Vincken, J.-P., 2015. Modification of prenylated stilbenoids in peanut (Arachis hypogaea) seedlings by the same fungi that elicited them: The fungus strikes back. J. Agric. Food Chem. 63, 9260-9268.

Araya-Cloutier, C., den Besten, H. M. W., Aisyah, S., Gruppen, H., Vincken, J.-P., 2017. The position of prenylation of isoflavonoids and stilbenoids from legumes (Fabaceae) modulates the antimicrobial activity against Gram positive pathogens. Food Chem. 226, 193-201.

Araya-Cloutier, C., Vincken, J.-P., van de Schans, M. G. M., Hageman, J., Schaftenaar, G., den Besten, H. M. W., Gruppen, H., 2018a. QSAR-based molecular signatures of prenylated (iso)flavonoids underlying antimicrobial potency against and membrane-disruption in Gram positive and Gram negative bacteria. Sci. Rep. 8, 9267.

Araya-Cloutier, C., Vincken, J.-P., van Ederen, R., den Besten, H. M. W., Gruppen, H., 2018b. Rapid membrane permeabilization of Listeria monocytogenes and Escherichia coli induced by antibacterial prenylated phenolic compounds from legumes. Food Chem. 240, 147-155.

Botta, B., Vitali, A., Menendez, P., Misiti, D., Delle Monache, G., 2005. Prenylated flavonoids: Pharmacology and biotechnology. Curr. Med. Chem. 12, 713-739.

Braga, L. C., Leite, A. A. M., Xavier, K. G. S., Takahashi, J. A., Bemquerer, M. P., Chartone-Souza, E., Nascimento, A. M. A., 2005. Synergic interaction between pomegranate extract and antibiotics against Staphylococcus aureus. Can. J. Microbiol. 51, 541-547.

Chang, J. C., Lai, Y. H., Djoko, B., Wu, P. L., Liu, C. D., Liu, Y. W., Chiou, R. Y. Y., 2006. Biosynthesis enhancement and antioxidant and anti-inflammatory activities of peanut (Arachis hypogaea L.) arachidin-1, arachidin-3, and isopentadienylresveratrol. J. Agric. Food Chem. 54, 10281-10287.

de Bruijn, W. J. C., Vincken, J.-P., Duran, K., Gruppen, H., 2016. Mass spectrometric characterization of benzoxazinoid glycosides from Rhizopus-elicited wheat (Triticum aestivum) seedlings. J. Agric. Food Chem. 64, 6267-6276.

Gibbons, S., 2004. Anti-staphylococcal plant natural products. Nat. Prod. Rep. 21, 263-277.

Hatano, T., Shintani, Y., Aga, Y., Shiota, S., Tsuchiya, T., Yoshida, T., 2000. Phenolic constituents of licorice. VIII. Structures of glicophenone and glicoisoflavanone, and effects of licorice phenolics on methicillin-resistant Staphylococcus aureus. Chem. \& Pharm. Bull. 48, 1286-1292.

Murphy, R. C., 2014. Chapter 1: Fatty acids. In: Murphy, R. C. (Ed.), Tandem mass spectrometry of lipids: Molecular analysis of complex lipids. The Royal Society of Chemistry, Cambridge, UK, pp. 1-39.

Park, B. H., Lee, H. J., Lee, Y. R., 2011. Total synthesis of chiricanine A, arahypin-1, trans-arachidin-2, transarachidin-3, and arahypin-5 from peanut seeds. J. Nat. Prod. 74, 644-649.

Popłoński, J., Turlej, E., Sordon, S., Tronina, T., Bartmańska, A., Wietrzyk, J., Huszcza, E., 2018. Synthesis and antiproliferative activity of minor hops prenylflavonoids and new insights on prenyl group cyclization. Molecules 23.

Royer, M., Herbette, G., Eparvier, V., Beauchene, J., Thibaut, B., Stien, D., 2010. Secondary metabolites of Bagassa guianensis Aubl. Wood: A study of the chemotaxonomy of the Moraceae family. Phytochemistry 71, 1708-1713.

Simons, R., Vincken, J.-P., Bakx, E. J., Verbruggen, M. A., Gruppen, H., 2009. A rapid screening method for prenylated flavonoids with ultra-high-performance liquid chromatography/electrospray ionisation mass spectrometry in licorice root extracts. Rapid Commun. Mass Spectrom. 23, 3083-3093.

Simons, R., Vincken, J.-P., Roidos, N., Bovee, T. F. H., van Iersel, M., Verbruggen, M. A., Gruppen, H., 2011. Increasing soy isoflavonoid content and diversity by simultaneous malting and challenging by a fungus to modulate estrogenicity. J. Agric. Food Chem. 59, 6748-6758.

Singhal, A. K., Sharma, R. P., Thyagarajan, G., Herz, W., Govindan, S. V., 1980. New prenylated isoflavones and a prenylated dihydroflavonol from Millettia pachycarpa. Phytochemistry 19, 929-934.

Sobolev, V. S., 2013. Production of phytoalexins in peanut (Arachis hypogaea) seed elicited by selected microorganisms. J. Agric. Food Chem. 61, 1850-1858.

Sobolev, V. S., Krausert, N. M., Gloer, J. B., 2016. New monomeric stilbenoids from peanut (Arachis hypogaea) seeds challenged by an Aspergillus flavus strain. J. Agric. Food Chem. 64, 579-584.

Sobolev, V. S., Neff, S. A., Gloer, J. B., 2009. New stilbenoids from peanut (Arachis hypogaea) seeds challenged by an Aspergillus caelatus strain. J. Agric. Food Chem. 57, 62-68.

Sobolev, V. S., Neff, S. A., Gloer, J. B., 2010. New dimeric stilbenoids from fungal-challenged peanut (Arachis hypogaea) seeds. J. Agric. Food Chem. 58, 875-881.

Sobolev, V. S., Potter, T. L., Horn, B. W., 2006. Prenylated stilbenes from peanut root mucilage. Phytochem. Anal. $17,312-322$. 
Trela, B. C., Waterhouse, A. L., 1996. Resveratrol: Isomeric molar absorptivities and stability. J. Agric. Food 381 Chem. 44, 1253-1257.

382 van de Schans, M. G. M., Vincken, J.-P., de Waard, P., Hamers, A. R. M., Bovee, T. F. H., Gruppen, H., 2016. Glyceollins and dehydroglyceollins isolated from soybean act as SERMs and ER subtype-selective phytoestrogens. J. Steroid Biochem. Mol. Biol. 156, 53-63. Yang, S. C., Tseng, C. H., Wang, P. W., Lu, P. L., Weng, Y. H., Yen, F. L., Fang, J. Y., 2017. Pterostilbene, a methoxylated resveratrol derivative, efficiently eradicates planktonic, biofilm, and intracellular MRSA by topical application. Front. Microbiol. 8, Article 1103. prenyltransferase utilizes dimethylallyl pyrophosphate from the plastidic terpenoid pathway. Plant Physiol. 171, 2483-2498. 


\section{$393 \quad$ Figures}

A<smiles>[R]c1ccc(/C=C/c2cc(O)cc(O)c2)cc1[R]</smiles>

$\mathrm{R}_{1}=\mathrm{H}, \mathrm{R}_{2}=\mathrm{H}$ : pinosylvin

$\mathrm{R}_{1}=\mathrm{OH}, \mathrm{R}_{2}=\mathrm{H}$ : resveratrol

$\mathrm{R}_{1}=\mathrm{OH}, \mathrm{R}_{2}=\mathrm{OH}$ : piceatannol

B<smiles>CC(C)/C=C/c1c(O)cc(/C=C/c2ccc(O)c(O)c2)cc1O</smiles><smiles>CC(C)/C=C/c1c(O)cc(/C=C/c2ccc(O)cc2)cc1O</smiles><smiles>CC1(C)C=Cc2c(O)cc(/C=C/c3ccc(O)cc3)cc2O1</smiles><smiles>CC(C)=CCc1c(O)cc(C=Cc2ccc(O)cc2)cc1O</smiles><smiles>CC1(C)C=Cc2c(O)cc(/C=C/c3ccc(O)c(O)c3)cc2O1</smiles><smiles>CC(C)=CCc1c(O)cc(/C=C/c2ccccc2)cc1O</smiles>

395 Figure 1. A, natural stilbenoids with a stilbene backbone. B, prenylated stilbenoids isolated in

396 this work: $\mathbf{1}$, arachidin-1; 2, arachidin-2; $\mathbf{3}$, arachidin-3; 4, arachidin-6; 5, arahypin-5; and $\mathbf{6}$,

397 chiricanine A. 
398 Table 1. Spectrometric and spectroscopic data of purified compounds as determined by UHPLC-PDA coupled to ESI-IT-MS and ESI-FTMS.

\begin{tabular}{|c|c|c|c|c|c|c|c|c|}
\hline \multirow[b]{2}{*}{ compound $^{\text {a }}$} & \multirow[b]{2}{*}{$\begin{array}{l}\lambda_{\max } \\
(\mathbf{n m})\end{array}$} & \multirow[b]{2}{*}{ ionisation } & \multicolumn{2}{|r|}{ IT-MS } & \multirow[b]{2}{*}{$\begin{array}{l}\text { molecular } \\
\text { formula }\end{array}$} & \multirow[b]{2}{*}{$m / z$ calc. } & \multicolumn{2}{|c|}{ FTMS } \\
\hline & & & $\begin{array}{l}m / z \\
\text { precursor }\end{array}$ & MS $^{2}$ product ions (relative abundance) ${ }^{b}$ & & & $m / z$ obs. ${ }^{\text {c }}$ & $\begin{array}{l}\text { error } \\
(\text { ppm })\end{array}$ \\
\hline \multirow[t]{2}{*}{$\mathbf{1}$} & 339 & {$[\mathrm{M}-\mathrm{H}]^{-}$} & 311 & $\begin{array}{l}\frac{241}{224}, 242(93), 312(76), 255(46), 267(45), 311(31), 293(25), \\
\text { (16) }\end{array}$ & $\mathrm{C}_{19} \mathrm{H}_{20} \mathrm{O}_{4}$ & 311.12888 & 311.12907 & 0.60 \\
\hline & & {$[\mathrm{M}+\mathrm{H}]^{+}$} & 313 & $\underline{257}$ & & & & \\
\hline \multirow[t]{2}{*}{2} & 322 & {$[\mathrm{M}-\mathrm{H}]^{-}$} & 295 & 239, 296 (55), $240(43), 226(42), 295$ (38) & $\mathrm{C}_{19} \mathrm{H}_{20} \mathrm{O}_{3}$ & 295.13397 & 295.13388 & -0.30 \\
\hline & & {$[\mathrm{M}+\mathrm{H}]^{+}$} & 297 & $\underline{241}$ & & & & \\
\hline \multirow[t]{2}{*}{3} & 338 & {$[\mathrm{M}-\mathrm{H}]^{-}$} & 295 & $\underline{239}, 240(48), 226(31), 295$ (26), 227 (25), 251 (18) & $\mathrm{C}_{19} \mathrm{H}_{20} \mathrm{O}_{3}$ & 295.13397 & 295.13402 & 0.18 \\
\hline & & {$[\mathrm{M}+\mathrm{H}]^{+}$} & 297 & $\underline{241}$ & & & & \\
\hline \multirow[t]{2}{*}{4} & 342 & {$[\mathrm{M}-\mathrm{H}]^{-}$} & 309 & $\underline{309}, 310(63), 265(60), 291(24), 294(21), 281$ (18) & $\mathrm{C}_{19} \mathrm{H}_{18} \mathrm{O}_{4}$ & 309.11323 & 309.11334 & 0.35 \\
\hline & & {$[\mathrm{M}+\mathrm{H}]^{+}$} & 311 & $\begin{array}{l}\frac{201}{269}, 283(55), 135(50), 187(40), 177(30), 293(29), 123(28), \\
(22), 183(20), 173(19), 265(17), 189(16), 202(16)\end{array}$ & & & & \\
\hline \multirow[t]{2}{*}{5} & 339 & {$[\mathrm{M}-\mathrm{H}]^{-}$} & 293 & $\underline{293}, 278(47), 294(35)$ & $\mathrm{C}_{19} \mathrm{H}_{18} \mathrm{O}_{3}$ & 293.11832 & 293.11847 & 0.52 \\
\hline & & {$[\mathrm{M}+\mathrm{H}]^{+}$} & 295 & $\begin{array}{l}\frac{201}{225}, 267(24), 239(23), 173(19), 159(18), 119(18), 249(15)\end{array}$ & & & & \\
\hline \multirow[t]{2}{*}{6} & 312 & {$[\mathrm{M}-\mathrm{H}]^{-}$} & 279 & $\underline{224}, 223(85), 279(66), 280(50), 211(15)$ & $\mathrm{C}_{19} \mathrm{H}_{20} \mathrm{O}_{2}$ & 279.13905 & 279.13914 & 0.31 \\
\hline & & {$[\mathrm{M}+\mathrm{H}]^{+}$} & 281 & $\underline{225}$ & & & & \\
\hline
\end{tabular}

399 a Data provided based on the trans isomer.

$400 \quad{ }^{\mathrm{b}}$ Most abundant fragment is underlined, only fragment ions with a relative abundance of at least 15 are shown.

$401{ }^{\mathrm{c}}$ Based on the average of 5 spectra in negative ionisation mode. 
402 Table 2. ${ }^{1} \mathrm{H}(600 \mathrm{MHz})$ and ${ }^{13} \mathrm{C}(150 \mathrm{MHz})$ NMR Spectroscopic data of arachidin-6 (4)

403 recorded in methanol-d 4 at $300 \mathrm{~K}$ ( $\delta$ in ppm, $J$ in $\mathrm{Hz})$.

\begin{tabular}{|c|c|c|}
\hline \multicolumn{3}{|c|}{ arachidin-6 (4) } \\
\hline position & $\delta_{\mathrm{C}}$, type & $\delta_{\mathrm{H}}$, mult. $(J \text { in } \mathrm{Hz})^{\mathrm{a}}$ \\
\hline 1 & $140.23, \mathrm{C}$ & \\
\hline 2 & $106.79, \mathrm{CH}$ & 6.418, bs \\
\hline 3 & $155.26, \mathrm{C}$ & \\
\hline 4 & $110.23, \mathrm{C}$ & \\
\hline 5 & $154.42, \mathrm{C}$ & \\
\hline 6 & $106.47, \mathrm{CH}$ & $6.475, \mathrm{~d}(1.3)$ \\
\hline$\alpha$ & $126.75, \mathrm{CH}$ & $6.721, \mathrm{~d}(16.2)$ \\
\hline$\alpha^{\prime}$ & $129.69, \mathrm{CH}$ & $6.889, \mathrm{~d}(16.2)$ \\
\hline $1^{\prime}$ & $131.02, \mathrm{C}$ & \\
\hline $2^{\prime}$ & $113.83, \mathrm{CH}$ & $6.974, \mathrm{~d}(2.0)$ \\
\hline $3^{\prime}$ & $146.51, \mathrm{C}$ & \\
\hline $4^{\prime}$ & 146.60, C & \\
\hline $5^{\prime}$ & $116.43, \mathrm{CH}$ & $6.737, \mathrm{~d}(8.2)$ \\
\hline $6^{\prime}$ & $120.27, \mathrm{CH}$ & $6.835, \mathrm{dd}(8.2,2.0)$ \\
\hline $1^{\prime \prime}$ & $118.23, \mathrm{CH}$ & $6.626, \mathrm{~d}(9.9)$ \\
\hline $2^{\prime \prime}$ & $129.10, \mathrm{CH}$ & $5.568, \mathrm{~d}(9.8)$ \\
\hline $3 "$ & 76.77, C & \\
\hline $4^{\prime \prime}$ & $28.01, \mathrm{CH}_{3}$ & $1.391, \mathrm{~s}$ \\
\hline $5^{\prime \prime}$ & $28.01, \mathrm{CH}_{3}$ & $1.391, \mathrm{~s}$ \\
\hline
\end{tabular}

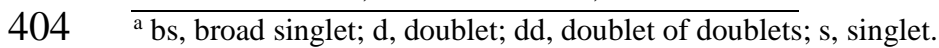


Table 3. Structural characteristics, purity, and antibacterial activity of piceatannol, resveratrol, pinosylvin and the purified prenylated stilbenoids against MRSA.

\begin{tabular}{|c|c|c|c|c|c|c|c|c|c|c|}
\hline \multirow[t]{2}{*}{ compound } & \multirow[t]{2}{*}{ precursor } & \multirow{2}{*}{$\begin{array}{l}\text { prenyl } \\
\text { configuration, } \\
\text { type }\end{array}$} & \multirow{2}{*}{$\begin{array}{l}\text { no. of } \\
\text { H-bond } \\
\text { donors }\end{array}$} & \multirow[t]{2}{*}{$\log _{7.2}{ }^{a}$} & \multicolumn{3}{|c|}{ purity $(\%)^{b}$} & \multirow{2}{*}{$\begin{array}{l}\text { MIC } \\
\left(\mu \mathrm{g} \mathrm{mL} \mathbf{L}^{-1}\right)\end{array}$} & \multirow{2}{*}{$\begin{array}{l}\text { TTD }_{25} \\
( \pm \text { StDev) } \\
\text { (h) }{ }^{\mathrm{c}}\end{array}$} & \multirow{2}{*}{$\begin{array}{l}\text { TTD }_{50} \\
( \pm \text { StDev) } \\
(h)^{c}\end{array}$} \\
\hline & & & & & $\mathbf{U V}_{\mathbf{3 1 0}}$ & MS (NI) & ${ }^{1} \mathrm{H}$ NMR & & & \\
\hline Piceatannol & n.a. & n.a. & n.a. & 3.06 & 99 & 99 & n.d. & $>200$ & $5.4( \pm 0.1)$ & $6.3( \pm 0.3)$ \\
\hline Resveratrol & n.a. & n.a. & n.a. & 3.38 & $\geq 99$ & 98 & n.d. & $>200$ & $6.0( \pm 0.1)$ & $6.9( \pm 0.7)$ \\
\hline Pinosylvin & n.a. & n.a. & n.a. & 3.69 & $\geq 99$ & $\geq 99$ & n.d. & $\leq 100^{\mathrm{d}}$ & n.d. ${ }^{\mathrm{d}}$ & n.d. ${ }^{\mathrm{d}}$ \\
\hline Arachidin-1 & pice & chain, $3 \mathrm{~m} 1 \mathrm{~b}$ & 4 & 4.93 & 87 & 88 & 80 & $>50$ & $6.1( \pm 0.6)$ & $8.4( \pm 0.5)$ \\
\hline Arachidin-2 & resv & chain, $3 \mathrm{~m} 2 \mathrm{~b}$ & 3 & 5.10 & 98 & 89 & 95 & $>50$ & $7.4( \pm 0.5)$ & $17.1( \pm 3.0)$ \\
\hline Arachidin-3 & resv & chain, $3 \mathrm{~m} 1 \mathrm{~b}$ & 3 & 5.23 & 80 & 63 & 60 & $>50$ & $6.6( \pm 1.2)$ & $8.6( \pm 1.8)$ \\
\hline Arachidin- 6 & pice & ring & 3 & 4.27 & 96 & 96 & n.d. & $50-75^{\mathrm{e}}$ & $11.5( \pm 2.2)$ & $21.5( \pm 0.5)->24^{\mathrm{e}}$ \\
\hline Arahypin-5 & resv & ring & 2 & 4.58 & 99 & 94 & 80 & $25-50^{\mathrm{e}}$ & $9.6( \pm 4.2)->24^{\mathrm{e}}$ & $>24$ ( \pm n.a. $)$ \\
\hline Chiricanine A & pino & chain, $3 \mathrm{~m} 2 \mathrm{~b}$ & 2 & 5.40 & 99 & 98 & 99 & $12.5^{\mathrm{e}}$ & $>24$ ( \pm n.a. $)$ & $>24$ ( \pm n.a. $)$ \\
\hline
\end{tabular}

n.a., not applicable; n.d., not determined; resv., resveratrol; pice, piceatannol; pino, pinosylvin; 3m1b, 3-methyl-1-butene, 3m2b; 3-methyl-2-butene.

${ }^{a} \log \mathrm{D}_{7.2}$, calculated octanol-water partitioning coefficient at $\mathrm{pH}$ 7.2, as calculated using MarvinSketch 17.2.27 with default settings.

${ }^{\mathrm{b}}$ Combined purity of the trans and cis isomers of the purified compounds. UV 310 , based on total peak area in UHPLC-PDA at $310 \mathrm{~nm}$; MS (NI), based on total peak area in UHPLC-ESI-MS negative ionisation mode ( $\mathrm{m} / \mathrm{z}$ range $200-1500) ;{ }^{1} \mathrm{H}$ NMR, based on the aromatic region in proton NMR spectroscopy.

${ }^{\mathrm{c}} \mathrm{TTD}_{25}$, time-to-detection at $25 \mu \mathrm{g} \mathrm{mL}^{-1}$; $\mathrm{TTD}_{50}$, time-to-detection at $50 \mu \mathrm{g} \mathrm{mL}^{-1}$.

${ }^{\mathrm{d}}$ Pinosylvin was only tested in the concentration range $100-400 \mu \mathrm{g} \mathrm{mL}^{-1}$ (one biological experiment, triplicate measurement).

${ }^{\mathrm{e}}$ Determined in four independent biological replicates, ranges indicate that MIC and TTD varied between experiments. 
Supplementary data with "Antibacterial activity of prenylated stilbenoids from peanut" by de Bruijn, ArayaCloutier, Bijlsma, de Swart, Sanders, de Waard, Gruppen, and Vincken

\section{Elution profiles reversed-phase chromatography}

\section{Pre-purification by RP-Flash Chromatography}

For Flash chromatography, samples were injected on a Reveleris C18 RP 80 g cartridge (particle size $40 \mu \mathrm{m}$ ) and eluents used were water (A) and $\mathrm{MeOH}(\mathrm{B})$, both with $1 \%(v / v)$ formic acid. Elution program: Isocratic at $48 \%$ B for $2.2 \mathrm{~min}$, linear gradient to $80 \%$ B from 2.2-74.8 min, linear gradient to $100 \%$ B from $74.8-77.0$ min, isocratic at $100 \%$ B from $77.0-88.0$ min.

\section{Preparative RP-HPLC-ESI-MS}

For preparative HPLC, samples were injected on a Waters XBridge Prep C18 OBD column (19 $\times 250 \mathrm{~mm}, 5 \mu \mathrm{m}$ particle size) (Waters, Milford, MA, USA) and eluents used were water (A) and ACN (HPLC-R grade) (B), both with 1\% ( $v / v)$ formic acid. The elution programs for the different compounds were as follows:

Compound 1: Isocratic at 37\% B for $3.68 \mathrm{~min}$, linear gradient to $47 \%$ B from 3.68-38.68 min, linear gradient to $100 \% \mathrm{~B}$ from $38.68-42.18 \mathrm{~min}$, isocratic at $100 \% \mathrm{~B}$ from $42.18-59.69 \mathrm{~min}$, linear gradient to $37 \%$ B from 59.69-63.19 min, isocratic at 37\% B from 63.19-80.96 min.

Compounds 2, 3, 4 and 5: Isocratic at 38\% B for 3.68 min, linear gradient to $48 \%$ B from 3.68$38.68 \mathrm{~min}$, linear gradient to $100 \% \mathrm{~B}$ from $38.68-42.18 \mathrm{~min}$, isocratic at $100 \% \mathrm{~B}$ from 42.18 59.69 min, linear gradient to $38 \%$ B from 59.69-63.19 min, isocratic at 38\% B from 63.19$80.96 \mathrm{~min}$.

Compound 6: Isocratic at $42 \%$ B for 3.68 min, linear gradient to $52 \%$ B from 3.68-38.68 min, linear gradient to $100 \% \mathrm{~B}$ from $38.68-42.18 \mathrm{~min}$, isocratic at $100 \%$ B from $42.18-59.69 \mathrm{~min}$, linear gradient to $52 \%$ B from 59.69-63.19 min, isocratic at 52\% B from 63.19-80.96 min. 
Supplementary data with “Antibacterial activity of prenylated stilbenoids from peanut" by de Bruijn, ArayaCloutier, Bijlsma, de Swart, Sanders, de Waard, Gruppen, and Vincken

\section{Analytical RP-UHPLC-PDA-ESI-IT-MS}

For analytical UHPLC coupled to ESI-IT-MS ${ }^{\mathrm{n}}$, samples were injected on a Waters Acquity BEH C18 $2.1 \times 150 \mathrm{~mm}, 1.7 \mu \mathrm{m}$ particle size column with a Waters VanGuard $2.1 \times 5 \mathrm{~mm}$ guard column of the same material. Eluents used were water (A) and $\mathrm{MeOH}(\mathrm{B})$, both with $0.1 \%(v / v)$ formic acid. Elution program: Isocratic at $48 \%$ B for $1.45 \mathrm{~min}$, linear gradient to 80\% B from 1.45-16.96 min, linear gradient to $100 \%$ B from $16.96-18.42 \mathrm{~min}$, isocratic at $100 \%$ B from 18.42-25.96 min. The eluent was adjusted to its starting composition in $1.18 \mathrm{~min}$, followed by equilibration for $7.27 \mathrm{~min}$.

\section{Analytical RP-UHPLC-PDA-ESI-FTMS}

For analytical UHPLC coupled to ESI-FTMS, samples were injected on a Waters Acquity BEH C18 $2.1 \times 150 \mathrm{~mm}, 1.7 \mu \mathrm{m}$ particle size column with a Waters VanGuard $2.1 \times 5 \mathrm{~mm}$ guard column of the same material. eluents used were water (A) and ACN (B), both with $0.1 \%(v / v)$ formic acid. Elution program: Isocratic at $20 \%$ B for $0.58 \mathrm{~min}$, linear gradient to $100 \%$ B from 0.58-47.18 min, isocratic at $100 \%$ B from 47.18-50.10 min. 
Supplementary data with "Antibacterial activity of prenylated stilbenoids from peanut" by de Bruijn, ArayaCloutier, Bijlsma, de Swart, Sanders, de Waard, Gruppen, and Vincken

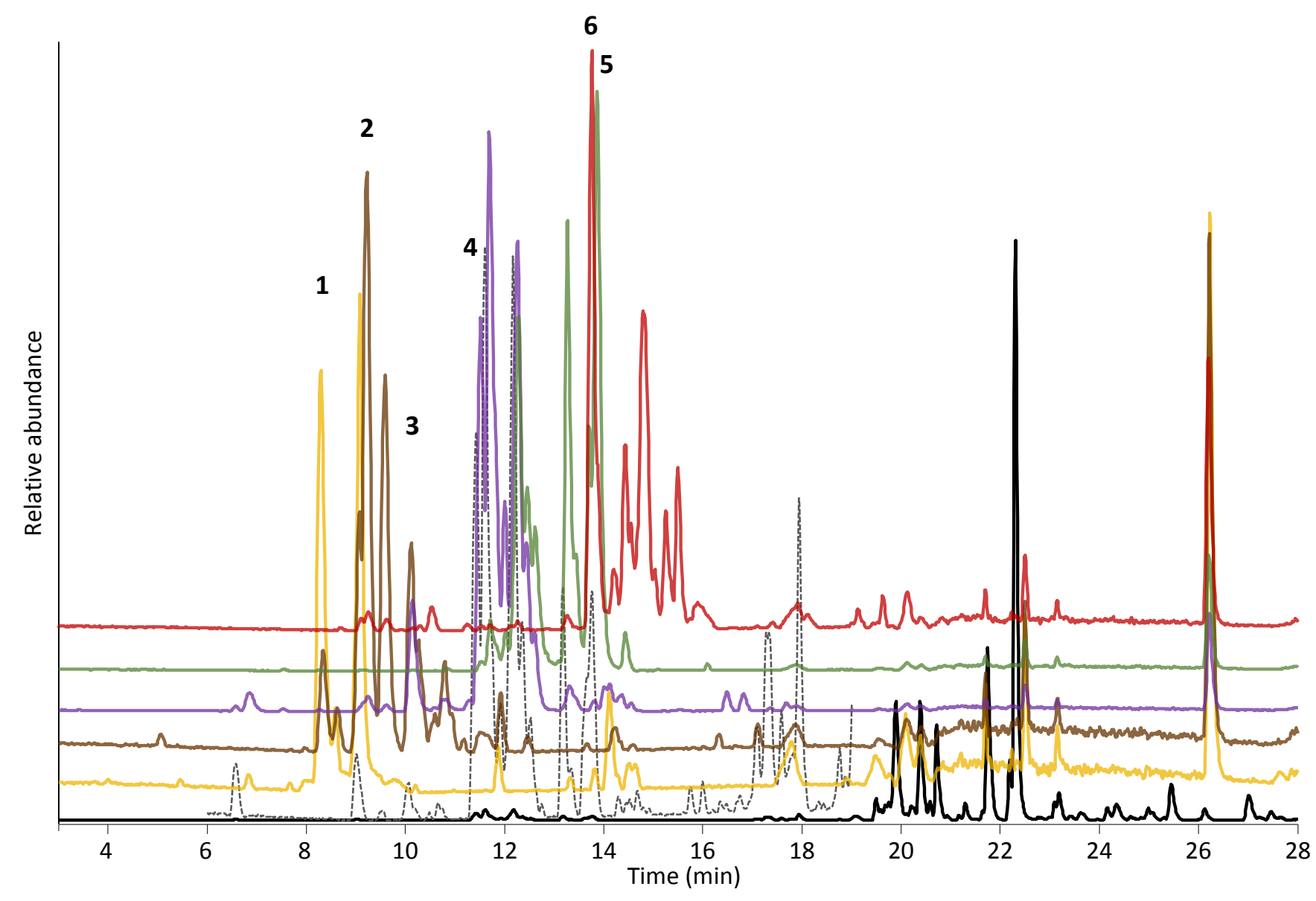

Figure S1. UHPLC-ESI-IT-MS negative mode $(\mathrm{m} / \mathrm{z}, 250-1000)$ chromatograms of cleaned peanut extract (black, full chromatogram; grey-dashed, zoom of 6-19 min) and pools obtained after Flash chromatography. Yellow, pool with compound 1; brown, pool with compounds 2 and 3; purple, pool with compound 4; green, pool with compound 5; and red, pool with compound 6. 
Supplementary data with "Antibacterial activity of prenylated stilbenoids from peanut" by de Bruijn, ArayaCloutier, Bijlsma, de Swart, Sanders, de Waard, Gruppen, and Vincken

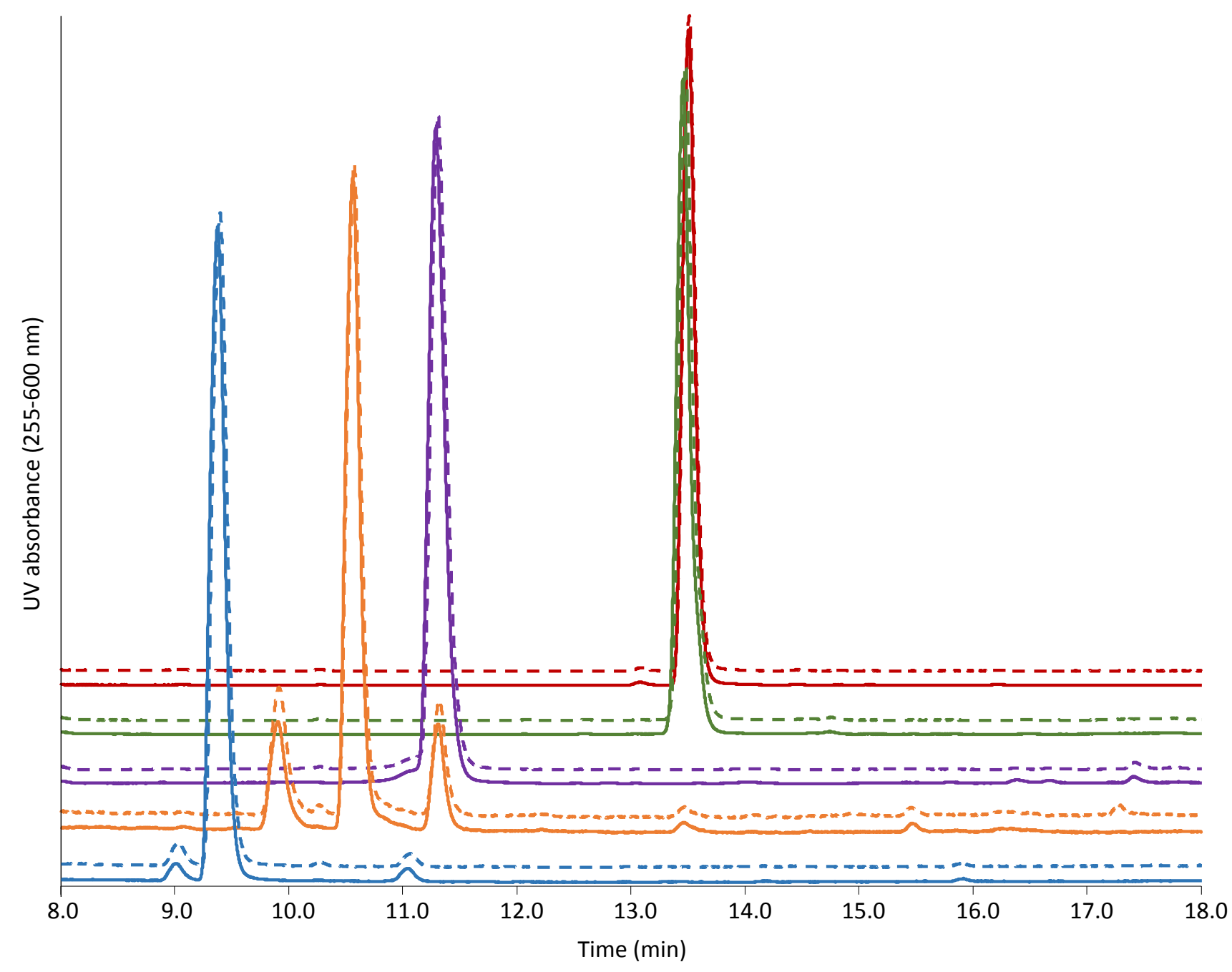

Figure S2. UHPLC-PDA (255-600 nm) chromatograms of compounds 2, 3, 4, 5 and 6 before (solid line) and after (dashed line) incubation for $24 \mathrm{~h}$ under antimicrobial assay conditions. Blue, arachidin-2 (2); orange, arachidin-3 (3); purple, arachidin-6 (4); green, arahypin-5 (5); and red, chiricanine A (6). 